[Type text]

\title{
Examining bushfire policy in action: Preparedness and behaviour in the 2009 Black Saturday fires
}

\author{
John Handmer ${ }^{1^{*}}$ and Saffron O'Neill ${ }^{2}$ \\ ${ }^{1}$ Centre for Risk and Community Safety, RMIT University, GPO Box 2476, Melbourne, \\ Victoria 3001, Australia. * Corresponding author: John.handmer@ rmit.edu.au. ${ }^{2}$ Geography, \\ College of Life \& Environmental Sciences, University of Exeter, Amory Building, Rennes \\ Drive, EX4 4RJ, UK, s.o'neill@exeter.ac.uk.
}

\begin{abstract}
An important part of reducing the risk of disaster is the preparedness of the people at risk. Australian bushfire authorities have policies and publicity about what households should do to be prepared - which include knowledge about fire risk, awareness of one's own risk, taking specific steps to reduce risk including having an emergency plan. Yet, there is sparse empirical evidence about the link between preparedness and actual behaviour in the face of a major disaster.
\end{abstract}

The authors had an opportunity to examine the circumstances surrounding the 172 civilian fatalities which occurred in the 2009 Victorian 'Black Saturday' bushfires, through the examination of a detailed fatality dataset compiled by the Victorian Bushfires Royal Commission. For the first time, this dataset allows detailed examination of Victorian bushfire safety policy ('Stay or go') in action on a day of extreme fire danger: from preparedness (both before and on the day of the fire) to behaviour on the day of the fire itself.

This analysis presents three overarching findings. First, some aspects of 'Stay or go' appear to be supported: being well-prepared to evacuate remains the safest option in a bushfire; sheltering passively is very dangerous; and well-prepared people undertaking active defence can potentially save themselves and their properties. Second, successful implementation of 'Stay or go' depends on a multitude of factors, which can challenge even the most capable householders. Third, extreme events like Black Saturday challenge the 'Stay or go' approach, and indicate the need for a different approach on extreme fire danger days. We conclude by reflecting on the findings from this research in terms of the most recent changes to bushfire policy in Victoria.

\section{Keywords}

preparedness, behaviour, wildfire, safety policy, vulnerability

\section{Highlights}

- Study examines preparedness and behaviour in the face of an extreme bushfire event

- Method uses unique fatality dataset comprising police, forensic and other records

- Preparation for bushfire requires triggers for action and contingency plans

- Understanding preparedness to defend is important in case evacuation becomes unsafe

- Community bushfire policy remains challenging, especially under climate change 


\section{Introduction}

It is orthodoxy amongst Australian and international emergency service agencies that those at risk need to be well prepared in order to undertake risk mitigation behaviour. Much effort is thus expended in communicating the nature of the risk, the need to plan for local circumstances (including having a household plan) and the need for emergency kit. For bushfire, specific behaviours may be advocated, such as the need to modify buildings and gardens to improve safety; or the need to leave an area in order to avoid danger on high-risk days (e.g. CFA 2013). Survey data shows that some (up to half in some areas) of the households in wildfire (or bushfire) prone areas have acted on such advice, and have taken wildfire related preparedness measures, including having a household plan (Whittaker et al. 2013, McLennan et al. 2015).

Problems can arise however in the quality or appropriateness of plans, how effective the preparedness approaches are, or how thoroughly people are able to implement their plans. Much published research on householder preparedness emphasises awareness, perception and knowledge of fire risk; and on measuring specific preparatory behaviours, such as having an emergency kit or a water pump for firefighting (McLennan et al. 2014). In effect, this research typically assesses preparedness on the basis of self-assessment of plans and intentions; whereas research examining preparedness against outcomes in the event of a fire is rare.

One study that has examined the relationship between preparedness and outcomes is Haynes et al. (2010). This Australian research drew on coronial reports of bushfire fatalities between 1900 and 2008, and showed that the majority of fatalities occurred as people were carrying out a planned action. This highlights that it is problematic to assume a direct link between preparedness (especially as measured by the proxy of having a fire plan) and effective riskmitigation behaviour when confronted by bushfire. However, the Haynes et al. paper did not examine the most recent, and catastrophic, Australian fire. The 2009 Black Saturday bushfires killed 172 civilians, had associated costs of over $\$ 3.5$ billion, and was proclaimed as Australia's worst bushfire disaster. Scholarly work has yet to examine how the relationship between preparedness and behaviour plays out in situations of extreme fire danger. Understanding this is especially important as anthropogenic climate change will drive both increased fire risk (through extended fire seasons and more severe fire weather; Clarke et al. 2011) and increased heat wave frequency and duration (Alexander and Arblaster 2009), impacting on people's ability to manage fire risk.

Here, we examine bushfire policy in action, through an exploration of preparedness and behaviour in the 2009 Black Saturday fires fatality dataset. This paper arose from the authors' involvement in the 2009 Victorian Bushfires Royal Commission, a public enquiry established after the fires. The authors were tasked to review the fatality data collected by the Commission immediately following the fires, and to examine "the implications of the fatality dataset for the "Stay or go" policy and for broader community safety action and communications" (Handmer et al. 2010: 9). To do so, the Commission provided access to a fatality dataset comprising police statements, forensic evidence and other material for each of the 172 civilian fatalities. In this paper, we analyse the fatality dataset using criteria for preparedness and behaviour developed from both bushfire safety policy documents and the research literature. This allowed us to examine bushfire policy in action on a day of extreme fire danger: from preparedness (both before and on the day of the fire) to actual behaviour on the day of the fire itself. 


\subsection{The evolution of the 'Stay or go' policy}

Householders staying and protecting their property during bushfires has a very long history, especially in rural Australia. Lived experience of those at risk of bushfire was that a building protected people from the radiant heat, smoke and embers of a bushfire as the firefront passed through the area; and that active defence of the property (for example, putting out spot fires in the roof eaves before and after the firefront passed over) ensured the viability of the building as a protective structure. This approach formed the basis of the policy 'Prepare, stay and defend, or leave early'; known colloquially as 'Stay or go'. This policy was formally adopted by all Australian fire agencies in 2005, although it had long been the unofficial position in some southern states.

To be effective, 'Stay or go' makes a number of major assumptions regarding the nature of fire risk including: that there is a single fire front which passes over the building within $~ 20$ minutes (during which people need protection from radiant heat) and that the property itself, and its location, result in a defendable structure (Lazarus and Elley, 1984). Academic work has shown that 'Stay or go' was a well-founded policy for historic data, in terms of protecting householders and property from fire risk (Handmer and Tibbits 2005; Handmer and Haynes 2008).

\subsection{Householder preparedness and 'Stay or go'}

The UN-ISDR (United Nations Office for Disaster Risk Reduction) defines preparedness as the 'knowledge and capacities [of people and institutions] to effectively anticipate, respond to, and recover from, the impacts of likely, imminent or current hazard events or conditions' (UN-ISDR 2007). As well as assumptions about property defendibility, and number and duration of fire fronts, the 'Stay or go' policy assumed a level of householder preparedness (e.g. CFA 2003; Tibbits et al. 2008).

First, 'Stay or go' assumed an awareness of the fire risk. People are unlikely to prepare unless they appreciate that a risk has relevance for them or their household. People may be unaware of bushfire risk if they are unfamiliar with a location: for example, if they are holidaymakers or recent migrants to an area.

Second, the policy assumed some knowledge to mitigate fire risk. This knowledge is both in preparation for, and in the event of, a fire. Preparatory activities might include modifications to buildings (such as installing water tanks and pumps, or water sprinkler systems) and gardens (such as cutting down overhanging trees, or planting non-flammable species) to improve risk management in the event of a fire. Knowledge also includes that needed to deal with an impending fire risk, such as the need to patrol the property to put out spot fires and prevent ember ignition if defending a property, or carrying drinking water and a blanket in a vehicle in order to more safely evacuate a fire-threatened area. Note that experience from previous knowledge of fire may act to inhibit appropriate response instead of facilitate effective risk-reduction behaviour: peoples' circumstances may be very different for different fire events, for example they may be much older, with an (unrecognised) subsequent reduction in firefighting ability (Kates, 1962).

Third, 'Stay or go' assumed that people had the capacity to actively defend their property. People needed to have the physical and mental capacity to undertake risk-reduction behaviours for their property before and during the fire event. If this was not the case (for an acute reason, such as consumption of alcohol; or for an ongoing reason, such as an long-term 
health issue or age), then it was assumed that they would evacuate rather than attempt to defend their property. The capacity to actively defend also depends on being able to defend a particular property during a bushfire. Property defence is impeded by the presence of heavy fuel loads close to the property (e.g. trees overhanging the house), a property on a slope of greater than $10^{\circ}$ (uphill slopes cause fire acceleration), and by large or complex property structures (for example, it is more difficult to detect ember attacks in multi-pitch roofs).

Last, the policy assumed the presence of a fire plan detailing clear, effective and appropriate behavioural intentions in the event of a fire. Making a fire plan requires some assessment of the costs, risks and benefits of the available options, and a commitment from all involved to follow a particular strategy in the event of a fire. Effective fire plans take into account different likely scenarios, for example, how a fire event will be handled for both regular weekday and weekend household schedules; as well as for other events (such as the presence of visitors, or a sudden family illness or injury). A contingency plan should also be present (e.g. what to do if the household's original intention to stay and defend becomes untenable). A known clear and specific trigger is required in order to implement the plan.

The policy mandated two options to mitigate risk from bushfire, preparing to stay and protect the building from the fire ('stay and defend') or preparing to evacuate the area early on a day of predicted fire danger ('leave early'). Other options were possible, but were not endorsed and are much more risky: for example, waiting to see what might happen ('wait and see') likely to lead to a dangerous last-minute evacuation in the face of a firefront; or sheltering from the fire without undertaking active defence ('sheltering passively') and risking the refuge building catching fire.

\subsection{Examining 'Stay or go' in a catastrophic bushfire}

This paper examines how 'Stay or go' was challenged by a catastrophic bushfire event, through the experience of the 'Black Saturday' bushfires.

Saturday 7 February 2009 brought the worst fire danger day in the Australian state of Victoria's history. The weather conditions were significantly worse than predicted with a record high in the state capital's (Melbourne) $\mathrm{CBD}$ of $46.4^{\circ} \mathrm{C}\left(2.5^{\circ} \mathrm{C}\right.$ hotter than the previous record), higher temperatures elsewhere in the state, very strong winds, and extremely low humidity (Karoly 2009). The day followed more than a decade of record-breaking hot and dry weather for the state: the hottest and longest drought, and the most severe heatwave on record the previous week (Karoly, 2009).

These severe weather conditions led to warnings during the preceding week that severe fires were likely on February 7 2009, including the warning that the day could see the worst fire danger risk ever recorded. The state Premier and the Chief Fire Officer both issued high profile warnings for the weekend of February 7-8, 2009. By early afternoon on February 7, these concerns were realised with several intense and very fast moving bushfires burning throughout the state. The fires claimed 172 civilian lives and about 2100 homes (VBRC, 2010a). They became known as the 'Black Saturday' bushfires.

To conclude, the 'Stay or go' policy approach makes a number of assumptions, both about the inherent defendibility of a property, and about the level of preparedness of people exposed to fire risk. We now examine levels of preparedness and actual behaviour associated with a catastrophic fire event, the 2009 Victorian Black Saturday bushfires. 


\section{Method}

The Victorian Bushfires Royal Commission provided a summary document for each of the 172 civilian fatalities. This material was based on detailed statements collected by the Police as part of their investigations into the fatalities from friends, family and neighbours of the deceased. These statements provided much detail about the level of preparations that people had attempted, both before and on the day of the fire. The mobile phone network remained operational throughout the fires in most locations, enabling people to communicate in the absence of landlines and electricity. The summaries included details of forensic investigations (for example, where and in what condition fatalities were found; whether there was evidence of firefighting equipment, including its possible failure; and so on). They detailed telephone and SMS text records, enabling accurate timestamps to be put on particular events (such as a last known location and time before death). Ongoing medical conditions of each fatality were construction of buildings for each location where there were fatalities.

Published material giving bushfire preparation advice is widely available from the Australian fire agencies (e.g. CFA 2008, CFA 2013, NSW RFS 2015). This includes information on how to prepare people and households for the risk of fire, and advice for dealing with the fire itself. In addition, the scholarly and policy literature on disaster and bushfire preparedness (as reviewed above) was consulted. This material was used to define a pilot coding scheme for analysing the fatality dataset, assisted by Damien Killalea, Director of Community Fire Safety, Tasmania Fire Service, a policy expert on community fire safety. The two authors then used the pilot coding scheme to undertake independent double-coding of 40 fatality cases. Each case was discussed in detail, and the coding scheme further refined. The authors then single-coded the remaining 92 cases, with any uncertainties raised and resolved through discussion. Percentages are of the total of 172 deaths. The final coding scheme is summarised below.

\subsection{Coding preparedness}

Activities were counted as preparing for the risk of fire when they were undertaken before February 7, 2009, and up to 1.30pm on the day of the fires. CFA (Country Fire Authority) bushfire preparedness material advises that preparations are completed before the day of fire arrival. However, the coding scheme recognised preparations on the day as having value. The $1.30 \mathrm{pm}$ cut off between preparedness and response was applied because this is when the Hume Highway (the main north-south route across the state) was closed by an out of control fire, and when fires started burning through the towns of Wallen and Whittlesea, rendering it too late for further substantial preparations. In assessing preparedness we looked for:

- Evidence of awareness of the risk (evidence required of fatalities discussing the general risk of bushfire; i.e. they knew they were in an area at risk from bushfires).

- Evidence of knowledge of actions to mitigate fire risk (evidence of knowledge of basic actions to mitigate fire risk; e.g. patrolling property to guard against ember attack, or evacuating the area early in a vehicle with drinking water and a blanket). This included recording evidence of whether the fatality had previous bushfire experience.

- Evidence of a fire plan. As a minimum, oral evidence of fatalities discussing a fire plan, though ideally, a written fire plan would exist. Evidence of the existence of a fire plan but with no details of what that plan contained was not sufficient.

- Evidence for a clear intention to act on the day (to stay and defend; leave; do nothing; wait and see; stay and shelter; or whether there were no intentions evident - and a trigger 
for action for implementing intentions); and any evidence as to why this intention changed on the day.

- The capacity to carry out intentions, as influenced by:

a. Presence of a chronic (e.g. mobility, heart disease) or acute (e.g. alcohol, drugs, fatigue) physical or mental disability pre-fire arrival

b. Age (12 years or under, or 70 years or older)

c. Likelihood of property defendability (were concerns raised by fire investigators over the property, e.g. in terms of likelihood of householders being able to defend in that location; or problems with proposed water delivery systems?)

- Level of preparedness:

a. Well prepared to stay and defend: Evidence of fuel management around the property; appropriate fire-fighting gear and clothing (minimum of buckets and mops); of an independent water supply (by one or more of a dam, tank, pool or creek. If properties did not have a gravity fed water supply, evidence was needed of a connected diesel or petrol pump, or an electric pump connected to a generator).

b. Some preparedness to stay and defend: Evidence of some fuel management, appropriate clothing and fire-fighting gear (minimum of buckets and mops) and of a small independent water supply (minimum of troughs or buckets around the property).

c. Well prepared to evacuate: Evidence of a clearly defined destination and trigger to leave.

d. Some preparation to evacuate: Evidence of a potential destination, and/or a vague trigger to evacuate.

e. No preparation: No evidence of any prior preparations.

\subsection{Coding behaviour on the day}

In coding behaviour on the day, we considered:

- Whether the person was taken by surprise (finding out that a fire was threatening less than one hour before the firefront arrived)

- Evidence of receiving a direct and official warning about fire; and whether they had activated their trigger for action

- Action at the time of death: sheltering passively (and in what location); undertaking some (may have been potentially questionable) defence; undertaking active defence; left late (whether on foot or vehicle); other activities (including doing nothing; death post-fire; travelling by car). Note that the coding scheme was non-exclusive, in that it allowed for multiple activities to be coded (so if there was some evidence of defence, but the fatality was found sheltering, it was coded under both 'some defence' and 'sheltering'). This more accurately captures the reality that many people did not simply commit to and undertake a single course of action on the day.

\section{Results and discussion: preparedness}

To recap, the policy assumed a number of preconditions for preparedness. First, people needed to be aware that there is a risk and know what to do about it. Second, based on this knowledge, they would have make a fire plan (including a contingency plan and a clear trigger for action) and have a clear intention to carry out a particular course of action. Third, for this sequence of events to be effective, those involved needed to have the mental and physical capacity to act; and if the plan is to stay and protect property, the property needed to be defendable. Preparedness results are summarised in Table 1. 


\subsection{Awareness and knowledge}

Awareness of bushfire risk was not universal, with a quarter of fatalities (24\%) not appearing to have even a basic knowledge that they were in an area at risk of bushfires. The knowledge criterion was set at a basic level, and yet a large minority of the fatalities (38\%) did not appear to meet this classification. In some cases, a lack of awareness may have been because fatalities were unfamiliar with the area. For example, some fatalities were house-sitting, and others were visiting the area. Nevertheless, there had been extensive media coverage of the danger the week before the fire. There was no evidence that prior experience of bushfires was an advantage. For many, the last significant bushfire experience is likely to have been the Ash Wednesday fires in 1983, 26 years previously.

\subsection{Plans and intentions}

There was evidence of a fire plan for around half (47\%) of the fatalities, although their quality was very variable. Few fire plans were comprehensive enough to address all the issues necessary to cope with conditions experienced on that day, or contained a contingency plan. Problems with fire plans included: fire plans not known by all household members; plans which only took account of people who were going to defend the property (not all occupants); fire plans which failed to account for the presence of visitors or other contingencies; and plans which set out high risk actions (e.g. planning to shelter in bathrooms). Some (12\%) intended to 'stay and defend' despite having no fire plan.

On intentions, a third (34\%) of fatalities intended to 'stay and defend' their properties, $8 \%$ intended to 'stay and shelter', and a quarter (26\%) intended to 'wait and see' before committing to a particular course of action. Some fatalities intended to 'leave' (16\%), though were often waiting for an unclear or unlikely trigger to evacuate. For a sizeable minority $(15 \%)$, there was no evidence of any intention to act. One fatality had made a conscious decision to do nothing.

\subsection{Capacity to act}

The capacity to carry out planned intentions is influenced by other factors, including the presence of a chronic or acute physical or mental disability, age, and the likelihood of property defendability.

About a quarter (24\%) of all fatalities had chronic clinical health conditions that possibly or definitely affected their mobility, judgment or stamina. This is broadly in line with state-wide figures, suggesting that the fatalities were not significantly more vulnerable than the general population (ABS 2004). Chronic physical health conditions in the dataset included degenerative diseases, morbid obesity and patients in recovery from medical procedures. Chronic mental health conditions included depression and post-traumatic stress disorder. Some fatalities had multiple conditions. A small proportion (5\%) of fatalities was affected by an acute physical or mental condition acquired on the day. These conditions included exhaustion from last-minute preparation in the extreme heat, and indicators of alcohol intoxication. The proportion of fatalities with these disabilities is probably under-estimated as the provision of medical evidence about people's condition on the day was limited.

Comparing the age distribution of residents in the 2009 fire affected area with the fatalities reveals longstanding patterns: far more older people (twice as many over 70 year olds) and far fewer children and teenagers (half as many under 20 years old) died than would be expected (Handmer et al. 2010). Younger people were more likely to be evacuated from the 
fire risk area, reducing the likelihood of juvenile deaths. Evidence from the transportation accident literature suggests declining vision and cognitive function (eg judgement, concentration and reaction time) may impact older adults driving ability (Owsley 2004; Merke Manual 2009), and this may play a role in increased senior deaths here, especially in conjunction with the increased vulnerability to heat with age (Worfolk 2000). Note that the gender split in the fatalities also reflected historical patterns (e.g. Haynes et al. 2010) with more men losing their lives than women (58\% versus $42 \%)$.

Police interviews and evidence from fire investigators indicated that almost a third of properties (32\%) were of questionable defendability due to proximity of fuel load, steep slopes, or property structure. It is unlikely that people would successfully defend such structures.

\subsection{Assessing preparedness}

Despite perhaps having intentions to act, a majority (58\%) of people had made no preparations, or had not actioned their plans, by the $1.30 \mathrm{pm}$ preparedness assessment cut off. Around a third of people were either somewhat prepared (14\%) or well prepared (20\%) to stay and defend. However, being classified as well prepared did not mean that fire-fighting plans did not have serious weaknesses: for example, fire plans were compromised by plastic hosepipe (which melted in the extreme heat), or by water pump placement on flammable wooden stands. Only $5 \%$ of people had prepared to evacuate, with almost all having made just some preparation - just one fatality was well prepared to leave (it is likely those well prepared to leave would have left early and survived).

\begin{tabular}{ll}
\hline Preparedness capacity & \% of fatalities \\
\hline Awareness of the risk & $24 \%$ \\
\hline Knowledge of actions to mitigate fire risk & $38 \%$ \\
\hline Presence of a fire plan & $47 \%$ \\
\hline Intentions pre-fire arrival & \\
Stay and defend & $34 \%$ \\
Stay and shelter & $8 \%$ \\
Leave & $16 \%$ \\
Wait and see & $26 \%$ \\
Do nothing & $1 \%$ \\
No discernible intentions & $15 \%$ \\
\hline Capacity to carry out intentions (questionable, due to): & \\
Chronic physical or mental disability & $24 \%$ \\
Acute physical or mental disability & $5 \%$ \\
Age ( $\leq 11$ years or ( $\geq 70$ years) & $25 \%(9 \%, 16 \%)$ \\
Property defendability & $32 \%$ \\
\hline Level of preparedness by 1.30pm on day of fire: & \\
Well prepared to stay and defend & $20 \%$ \\
Some preparedness to stay and defend & $14 \%$ \\
Well prepared to evacuate & $<1 \%$ \\
Some preparation to evacuate & $5 \%$ \\
No preparation & $58 \%$ \\
\hline
\end{tabular}

Table 1. Levels of preparedness pre-fire arrival in the fatality dataset. Note 'Level of preparedness' does not sum to $100 \%$ because of a lack of evidence to categorise some cases.

\section{Results and discussion: Behaviour}


Taking into account levels of awareness, knowledge, fire planning and intentions - mediated by capacity - what was the actual behaviour of the fatalities in the time leading up to their deaths? Results are summarised in Table 2.

\subsection{Fatality behaviour}

Police statements indicate that there was much activity after the $1.30 \mathrm{pm}$ preparedness cut off. This included activities for defence (e.g. hosing down the area around the property, filling roof gutters with water, clearing flammable debris from around the property, sorting out fire pumps, and changing into appropriate clothing) as well as for evacuation (such as packing cars with valuables, or trying to locate household pets). 'Stay or go' assumed most of these activities would have been undertaken well in advance, and not as the firefront was arriving. Leaving these activities until the last minute on a $46^{\circ}$ day would be likely to induce stress and exhaustion.

Over two thirds $(69 \%)$ of the fatalities were sheltering at the time of death. Indications of sheltering rather than active defence included the position of bodies (such as in the bath), indicating passive sheltering rather than active defence; and that fatalities were not found near evidence of a means of firefighting (such as a bucket handle, or holding a hosepipe). Over a quarter (27\%) of the fatalities were found sheltering in a bathroom, or other small room with just one exit (such as a cool room or laundry). Police statements record some fatalities being advised to shelter in the bathroom by friends, family or officials. In some cases, this was a last-minute decision as the fire encroached, but for others, it appeared to form part of their intentions, or was even part of their fire plan. A smaller proportion (8\%) was sheltering in sheds, outhouses, spas, shelters or bunkers. In some cases, although the shelter itself did not burn, the people inside were overcome by toxic gases. The remaining $34 \%$ of fatalities were sheltering elsewhere within the house, or their exact location within the property could not be determined.

The coding scheme was non-exclusive, in that it allowed for multiple activities to be coded. Thus, where it appeared fatalities had been undertaking some defence but were found sheltering, the case was coded under both 'sheltering' and 'questionable/some defence'. Almost a fifth (19\%) of all fatalities were sheltering but had perhaps undertaken some defence. However, the evidence for defence is often unclear, and defensive actions often appeared to be minimal.

A significant minority (29\%) had undertaken either 'some defence' (24\%) or 'active defence' $(5 \%)$. Evidence for 'active defence' was found in police statements about preparation and equipment checks (e.g. neighbour witness statements about checking water pumps were in working order); or forensic evidence of actions being undertaken to defend property at the time of death (e.g. water taps in the 'on' position feeding a pump and connected to a hose, near to where the fatality's body was found). Indications for 'questionable or some defence' included evidence of some fire-fighting activity in the time leading up to (but not at the time of) death (e.g. a water pump failure as the fire-front arrived causing a retreat to shelter; or where fatalities were found sheltering but next to firefighting gear such as hoses or buckets).

A contributing factor in some deaths appears to have been lack of appropriate clothing. Some people and children, especially if expecting to leave, were wearing little more than bathing costumes. This left them exposed to the full force of the fire's radiant heat and to the risk of 
fatal burns. It highlights how preparedness behaviour for one extreme event (heat) can increase risk of another (fire).

\begin{tabular}{ll}
\hline Behaviour & \% of fatalities \\
\hline Taken by surprise & $30 \%$ \\
\hline Received a direct and official warning & $9 \%$ \\
\hline Action at the time of death & \\
Active defence & $5 \%$ \\
Some (or questionable) defence & $24 \%$ \\
Evacuating by foot & $9 \%$ \\
Evacuating in a vehicle & $5 \%$ \\
Sheltering passively, in: & \\
$\quad$ Small room with one exit (e.g. bathroom, laundry) & $27 \%$ \\
$\quad$ Inside property (general, or exact location not specified) & $34 \%$ \\
$\quad$ Structure separate to property (e.g. bunker, shed, spa) & $8 \%$ \\
Other (e.g. dealing with livestock, camping, death post-fire) & $9 \%$
\end{tabular}

Table 2. Behaviour on the day categorised from the fatality dataset. Note that the coding scheme was non-exclusive, in that it allowed for multiple activities to be coded, so 'Action at time of death' does not sum to $100 \%$.

\subsection{Comparing intentions and behaviour}

The difference between intentions and behaviour indicates a number of issues that prevented plans from being fully implemented. These factors included: being taken by surprise, having an inadequate trigger to implement plans; and last-minute disagreements over planned actions.

There is considerable evidence of fatalities being taken by surprise either by a threatening fire's existence, or by the fire arriving much sooner than expected. A significant minority (at least $30 \%$ ) were taken by surprise by the existence of a threatening fire (defined as less than an hour between finding out and time of death), despite some of those fatalities having made a fire plan and having been classified as 'well prepared'. It is likely that a significantly larger proportion was surprised by the fire's intensity, rate of spread and the length of time taken for the front to pass (Whittaker et al. 2013). This is particularly the case for the fatalities that occurred following the late change in wind direction and sudden arrival of the firefront from a different direction. Whilst the wind change was well forecast, there was just 18 minutes from the wind change to the average time of the 34 deaths in the town of Marysville (VBRC 2010b).

Activation requires some sort of trigger, which may be a specific warning or a high level of perceived threat. It appears that many people did not fully activate their plans, even disregarding the $1.30 \mathrm{pm}$ preparedness cut off criterion. There was a widespread assumption that people would receive an official warning, or that they could obtain help by calling the national emergency number, triple zero. On the day of the fire, $72 \%$ of emergency calls went unanswered (VBRC 2009: 294), with few (if any) receiving assistance after calling. Just 9\% of fatalities appeared to have received a warning about the fire directly from an official source. However, nearly all were warned by neighbours, friends or relatives, or saw signs of a large fire approaching, and there had been extensive high profile media coverage of the risk over the preceding few days.

There is evidence of household disagreements as the fire approached. In virtually all cases this was between women who wanted to leave, and men who wanted to stay and defend. In some cases it appears that the difference in opinion was long standing, in other cases it was 
occurred when the fire was imminent. Last-minute changes of plans can lead to late evacuation, which is a dangerous option (Handmer and Tibetts 2005).

\section{Conclusions}

The authors had an opportunity to examine the circumstances surrounding bushfire fatalities, through the examination of a detailed fatality dataset compiled by the Victorian Bushfires Royal Commission. This dataset has enabled an investigation of householder preparedness and behaviour in the face of a devastating bushfire; and to examine bushfire public policy in action. There are three main conclusions with regard to the 'Stay or go' approach.

First, some aspects of 'Stay or go' appear to be supported by this analysis of the fatality dataset. The almost complete absence of fatalities that were well-prepared to evacuate indicates that this is the safest option in a potential bushfire situation, especially in extreme conditions. The high proportion of fatalities apparently sheltering passively indicates that this is a highly dangerous option. And, there were few deaths of people undertaking active defence - so we may conclude that alert and capable well-prepared people can save themselves and their properties from bushfire. These findings align with those of Haynes et al. (2010).

Second, successful implementation of 'Stay or go' depended on some challenging assumptions: those at risk understanding the risk and their limitations, knowing what to do, being well prepared physically and mentally, being alert for sudden changes, being decisive, and having multiple fall-backs or contingency plans. Properties needed to be well prepared and defendable, and agencies needed to provide timely warnings and information on appropriate action. All this needed to be accomplished without formal training for those at risk. The findings presented here show that there are many links in the chain of preparedness, and any one of them breaking can lead to fatal consequences. In particular, the considerable number of fatalities found sheltering passively in a bathroom or similar indicates an area where public education is required. Other actions could include fire agencies supporting those who are especially vulnerable, including those for whom staying is not an option even in minor fires. Individualised advice on property defendability, as has occurred in Tasmania, is also important.

Last, the severity of the Black Saturday fires challenged the 'Stay or go' approach. Despite warnings stressing the severity of the risk, there was a lack of appreciation that the state faced exceptional conditions. Many people could not develop and implement appropriate effective preparations and action, because of a mismatch between their plans and capacities and the conditions on the day, because of the defendability of their properties, or because of a lack of contingency plans if their preferred plan became untenable. This situation is especially pressing in light of the likelihood of longer fire seasons and more extreme fires under climate change (O’Neill and Handmer 2012).

\section{Policy reflections}

The Victorian Bushfires Royal Commission presented its final report in 2010, and many changes to bushfire risk management have occurred since. Several of their Recommendations have relevance for the discussion in this paper: first, that people with identifiable vulnerabilities should be supported by fire agencies; second, that 'unacceptably high bushfire risk' locations be abandoned; and third, that warnings should be improved. Warnings were 
changed by fire agencies before the Commission issued its recommendations, however, the first two recommendations have seen little change.

Policy changes have also occurred in response to the fires and the Commission's recommendations. The 'Stay or go' approach was changed to emphasise leaving early and the importance of thorough preparation with the catch phrase: 'Prepare, act, survive'. The approach was still essentially binary though and had trouble coming to grips with the everyday complexity of living in a fire risk area (Rhodes 2014, Proudley 2010) and safety related actions (Whittaker et al., 2013). For example, survey data from the time around Black Saturday show that while most people knew that they were expected to leave early on exceptionally severe fire risk days, only around $2 \%$ actually did so (Whittaker and Handmer 2010). Recent analysis shows little change in the proportion of people who actually leave early on exceptionally risky days (McLennan et al. 2015).

In 2014, the Victorian approach to community bushfire safety changed again, to 'Leave and live'. This is a clear change of emphasis to leaving early as the safest option. However, challenges remain. People still need to be prepared, to have clear triggers to leave, and not to 'wait and see' how the situation develops. A challenge for policy and fire agencies is to ensure people maintain preparedness to stay as a contingency plan, in case they cannot leave due to a sudden fire or access closure. A major challenge to 'Leave and live' is that (especially if days of very high fire danger become more frequent under climate change), leaving early 'just in case' on all days of extreme danger becomes seen as too disruptive to peoples' lives and livelihoods and so people increasingly risk staying in the fire danger area.

\section{References}

ABS (2004) (cat. no. 4430.0) Study on Disability, Aging and Carers. http://www.ausstats.abs.gov.au/Ausstats/subscriber.nsf/0/978A7C78CC11B70 2CA256F0F007B1311/\$File/44300_2003.pdf (accessed 2 April 2015).

Alexander, L. \& Arblaster, J. (2009) Assessing trends in observed and modelled climate extremes over Australia in relation to future projections International Journal of Climatololgy 29, 417-435

CFA. (2003). Position paper on evacuation during bushfires, Country Fire Authority: Melbourne.

CFA (2008) Living with fire: Victoria's bushfire strategy. Country Fire Authority: Melbourne.

CFA (2013) Fire ready kit. Melbourne: Country Fire Authority. http://www.cfa.vic.gov.au/fm_files/attachments/plan_and_prepare/frk_2013/4 713_CFA_2014_FireReadyKit_web.pdf (accessed 25 Mar 15)

Clarke, H.G., Smith, P.L. \& Pitman, A.J. (2011) Regional signatures of future fire weather over eastern Australia from global climate models. International Journal of Wildland Fire 20, 550-562

Handmer, J. \& Tibbits A. (2005) Is staying at home the safest option during wildfire? Historical evidence for an Australian approach. Environmental Hazards 6, 8191.

Handmer J \& Haynes K (Eds.) (2008) Community bushfire safety. CSIRO Publishing: Melbourne.

Handmer, J. O'Neill, S.J. \& Killalea, D. (2010) Review of fatalities in the February 7th 2009 bushfires: A report prepared for the Victorian Bushfires Royal Commission April 
[Type text]

2010. Centre for Risk \& Community Safety, RMIT, and Bushfire Cooperative Research Centre.

Haynes, K., Handmer, J., McAneney, J., Tibbits, A. \& Coates, L. (2010) Australian bushfire fatalities 1900-2008: exploring trends in relation to the 'Prepare, stay and defend or leave early' policy. Environmental Science \& Policy 13, 185194

Karoly, D. J. (2009). The recent bushfires and extreme heat wave in south-east Australia. Bulletin of the Australian Meteorological and Oceanographic Society, 22, 10-13 http://www.amos.org.au/documents/item/165 (accessed 28/04/15)

Kates, R. W. (1962) Hazard and choice perception in flood plain management, (Research Paper No. 78), Chicago: University of Chicago, Department of Geography

Karoly, D.J. (2009) The recent bushfires and extreme heat wave in southeast Australia. Bulletin of the Australian Meteorological and Oceanographic Society $22,10-13$

Lazarus, G. \& Elley, J. (1984) A study of the effect of household occupancy during the Ash Wednesday Bushfire in Upper Beaconsfield, Victoria, February 1983, National Centre for Rural Fire Research: Technical Paper No. 3

McLennan J., Elliot, G. \& Wright, L. (2014) Bushfire survival preparations by householders in at-risk areas of south-eastern Australia. Australian Journal of Emergency Management. Volume 29 Issue 2, 2014. https://ajem.infoservices.com.au/items/AJEM-29-02-05 (accessed 25 Mar 15)

McLennan, J., Paton, D. \& Wright, L. (2015) At-risk householders' responses to potential and actual bushfire threat: An analysis of findings from seven Australian post-bushfire interview studies 2009-2014. International Journal of Disaster Risk Reduction. doi: 10.1016/j.ijdrr.2015.02.007

Carr, D.B. (2009) The older driver. Merke Manual. http://www.merckmanuals.com/home/older-people-s-health-issues/the-olderdriver/the-older-driver (accessed 20/04/15)

NSW RFS (2015) Plan and prepare. Sydney: NSW Rural Fire Service. http://www.rfs.nsw.gov.au/plan-and-prepare (accessed 25 Mar 15)

Owsley, C. (2004) Driver capabilities in transportation in an aging society: A decade of experience. Technical Papers and Reports from a Conference: Bethesda, MD; Nov. 7-9, 1999. Washington, DC, Transportation Research Board

O’Neill, S.J. \& Handmer, J. (2012) Responding to bushfire risk: the need for transformative adaptation. Environmental Research Letters 7, 014018

Proudley, M. (2010) Fire, families and decisions: Exploring the bushfire experience from a domestic perspective. VDM Publishing

Rhodes, A. (2014) "Why don't they do what we think they should?" Understanding people's response to natural hazards. AFAC 2014 Conference Proceedings Day 3. Wellington. http://www.afac.com.au/downloaddoc.aspx?q=1e0075744663-4b51-a17e-6280b108412e (Accessed 25 Mar 15)

Tibbits, A, Handmer J, Haynes K., Lowe T. \& Whittaker J. (2008) Prepare, stay and defend or leave early: evidence for the Australian approach. In Handmer, J. and Haynes, K. (Eds.) Community bushfire safety. CSIRO Publishing: Melbourne: $59-76$

VBRC (2009) Interim Report. Victorian Bushfire Royal Commission. http://www.royalcommission.vic.gov.au/getdoc/42297fbe-abce-4188-8bc9197bd49ad3c0/High-Resolution-Version.html (Accessed 02/04/15) 
[Type text]

VBRC- Final Report: Summary (2010a) Final Report Summary. http://www.royalcommission.vic.gov.au/finaldocuments/summary/PF/VBRC_ Summary_PF.pdf (Accessed 25/03/15)

VBRC (2010b). Final Report Vol 2: Fire preparation, response and recovery. Melbourne: Victorian Government. http://www.royalcommission.vic.gov.au/finaldocuments/volume2/PF/VBRC_Vol2_Chapter01_PF.pdf (Accessed 25/03/15)

UN-ISDR (2007) United Nations Office for Disaster Risk Reduction: Terminology. http://www.unisdr.org/we/inform/terminology. (Accessed 17/04/15).

Whittaker, J. \& Handmer, J. (2010) Community bushfire safety: a review of postBlack Saturday research. The Australian Journal of Emergency Management 25, 7-13

Whittaker, J., Haynes, K., Handmer, J. \& McLennan, J. (2013). Community safety during the 2009 Australian 'Black Saturday' bushfires: an analysis of household preparedness and response. International Journal of Wildland Fire 22, 841-849

Worfolk, J.B. (2000) Heat Waves: Their Impact on the Health of Elders. Geriatric Nursing, 21 (2), $70-77$

\section{Acknowledgments}

This paper draws on research undertaken for the Victorian Bushfires Royal Commission through the Bushfire Cooperative Research Centre (CRC) (see Handmer, O'Neill and Killalea 2010). Thanks to the staff and counsel of the Royal Commission, Richard Thornton (previously Bushfire CRC), and Andrew Wilson (previously DEPI) for their comments on the original report. Our thoughts remain with the families and friends of the 172 civilian fatalities on which this paper reports.

The project was funded by the Victorian Bushfires Royal Commission through the Bushfire Cooperative Research Centre. The Commission was involved in the project in an oversight capacity, in particular to ensure that strict confidence was maintained, and that conflicts of interest were avoided. Writing of this paper was supported through Saffron O'Neill's ESRC Fellowship (S/K001175/1). 